\title{
Plasma-assisted ignition for a kerosene fueled scramjet at Mach 1.8
}

\author{
Fei Li ${ }^{a}$, Xi-long Yu ${ }^{a}{ }^{*}$, Ying-gang Tong ${ }^{b}$, Yan Shen ${ }^{b}$, Jian Chen ${ }^{b}$, Li-hong Chen ${ }^{a}$, \\ Xin-yu Chang ${ }^{\mathrm{a}}$ \\ a State Key Lab of High Temperature Gas Dynamics, Institute of Mechanics, Chinese Academy of Sciences, Beijing 100190, China \\ b Beijing Institute of Control Engineering, Chinese Academy of Space Technology (CAST), Beijing 100080, China
}

\section{A R T I C L E I N F O}

\section{Article history:}

Received 6 January 2012

Received in revised form 6 August 2012

Accepted 25 October 2012

Available online 29 October 2012

\section{Keywords:}

Scramjet

Kerosene fuel

Plasma torch

Ignition

\begin{abstract}
A B S T R A C T
By using a plasma jet (PJ) torch with $1.5 \mathrm{~kW}$ input power as an igniter, successful ignition for liquidkerosene fueled combustion experiment was conducted in a direct-connected supersonic test facility. The incoming flow has total temperature of $950 \mathrm{~K}$ and local Mach number of 1.8, corresponding to Mach 4 flight condition. In this study, several optical techniques, including high speed photography, high speed schlieren photography, and planar laser scattering (PLS) technique, were combined to study the ignition process, flame propagation, and mixing features of liquid kerosene fuel with air around the cavity. The effect of fuel injection position, injection pressure, and feedstock gas on ignition performance has been analyzed. The results indicate that local mixing is a critical factor for ignition. It is also shown that the PJ torch with $\mathrm{N}_{2}+\mathrm{H}_{2}$ feedstock is superior to the PJ torch with $\mathrm{N}_{2}$ feedstock for the ignition of liquidkerosene fuel. These results are valuable for the future optimization of kerosene-fueled scramjet engine when using a PJ torch as an igniter.
\end{abstract}

(c) 2012 Elsevier Masson SAS. All rights reserved.

\section{Introduction}

In scramjet, supersonic gas flow passes through the engine within very short time (generally in millisecond magnitude). Thus, it is of great importance to accelerate the combustion to ensure full heat release and stable combustion under such a hostile condition [2], especially at low Mach number flight condition, where ignition is the most critical problem for combustor design due to the low stagnation temperature $[14,16]$. To overcome the ignition difficulty in supersonic flow, application of both thermo-equilibrium and non-equilibrium plasma to supersonic combustion has become an active research field in recent years $[5,11,13,22,27,30]$. The plasma can not only facilitate the easy ignition of fuel/air mixture but also the acceleration of combustion process, which are crucial for the sustainability of stable combustion in supersonic free stream.

Thermo-equilibrium plasma generator, the plasma jet (PJ) torch, contains large amount of radicals in the high temperature plasma gas and enjoys several potential advantages for combustion enhancement as a supersonic igniter $[8,9,11,15,24,27]$. The former studies mostly focused on the effects of feedstock [15,19,21], location of fuel injector [9] and airflow parameters on ignition characteristics for both hydrogen and hydrocarbon fuels. For hydrogen and low carbon number hydrocarbon fueled scramjet, the PJ torches have been successful demonstrated in scramjet test facilities $[9,15,26]$. However, the capability of PJ torches for high carbon

\footnotetext{
* Corresponding author.

E-mail address: xlyu@imech.ac.cn (X.-l. Yu).
}

number hydrocarbon (like kerosene) fueled scramjet has not been fully investigated [1]. For practical applications, kerosene fueled scramjet is much more promising for future aerospace propulsion systems and military objectives due to its high enthalpy, high density and easy storage under room conditions $[12,28]$. Normally, in scramjet ground tests fueled with kerosene, small amount of $\mathrm{H}_{2}$ or other pyrophoric liquid is added as piloted ignition of source $[4,29]$. These techniques are effective, but the additional storage, control and delivery system can introduce system complexity. For this reason, study on application of the PJ torch to kerosene fuel without piloted additives is still a crucial issue [1,20].

For supersonic combustion, the global ignition concept is introduced for the definition of successful ignition [8]. That means, pre-combustion shock train can be established upstream of fuelinjection/flame-holding, and the resulting heat release in the combustion chamber make this process self-sustaining, and also there is no too much backpressure for un-starting of engine inlet. According to this definition, successful ignition means shock train is maintained through separated boundary layer and flame propagated in the whole combustion chamber.

This paper concentrates on the usage of plasma torch (PJ) as an igniter for a kerosene-fueled scramjet at Mach 1.8 without piloted additives. The ignition and flame propagation in the combustor are investigated with both high speed photography and high speed schlieren photography. Besides the influence of the PJ torch placement relative to fuel injection sites, the effect of injection pressure and plasma torch feedstock on ignition are reviewed in detail. In order to study the effect of local equivalence-ratio on ignition, fuel 


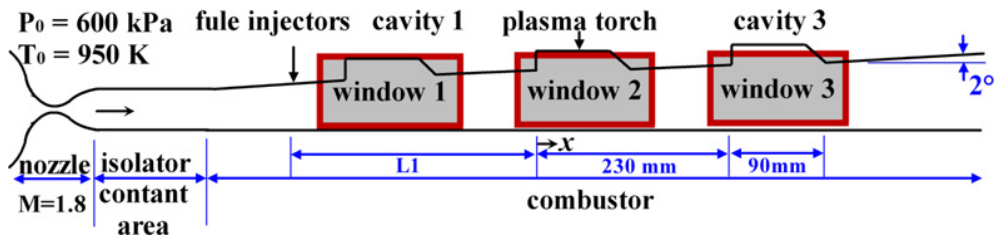

Fig. 1. Schematic diagram of direct-connected supersonic combustion test facility.

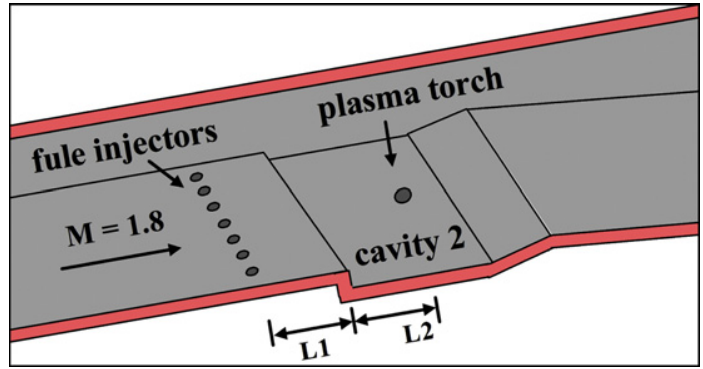

Fig. 2. Injector/cavity configuration with simulated plasma torch.

droplets distribution near cavity are obtained and analyzed by using planar laser scattering technique.

\section{Experimental facility}

The configuration of a direct-connected supersonic combustion test facility is shown in Fig. 1. High enthalpy flow was generated through vitiated heater, and accelerated to the designed Mach number $(\mathrm{Ma}=1.8$ in this paper) through a convergent-divergent nozzle [7]. The stagnation pressure and temperature of the incoming flow gas were $0.6 \mathrm{MPa}$ and $950 \mathrm{~K}$, respectively. Flow rate of the test gas was $1.2 \mathrm{~kg} / \mathrm{s}$ and the effective test time was about two seconds. In the combustor, fuel was injected into the supersonic flow and mixed with the vitiated air. The dimension of the rectangular cross section was $40 \mathrm{~mm} \times 85 \mathrm{~mm}$. The bottom wall of combustor was a flat plate, while the top wall had a 2-degree divergent angle.

Wall fuel jet injection with cavity flameholders is considered to be a desirable configuration for scramjet combustor due to the low pressure losses and cooling requirements [18]. Since flameholding mode and reaction zone vary with the increasing of Mach number, multiple cavities are normally used for better organization of heat release $[3,17]$. In current work, three cavities were installed in this top wall, as shown in Fig. 1, and the distance between two neighboring cavities was $230 \mathrm{~mm}$. The dimension of cavities was
$18 \mathrm{~mm}$ in depth and $90 \mathrm{~mm}$ in length, with 45 degree slope angle in the rear wall. Liquid kerosene fuel was injected into main flow through seven small holes with diameters of $0.5 \mathrm{~mm}$. Quartz windows were mounted on the opposite sides of the each cavity for the optical measurements, as shown in Fig. 1. Besides the optics, the isolator and combustor were also equipped with thirty static pressure transducers. These pressure transducers provided a static pressure distribution along the flow direction.

A water-cooled direct arc PJ torch was installed in Cavity 2. The detailed arrangement of the injection holes, PJ torch, and Cavity 2 are shown in Fig. 2. L1 represents the adjustable distance between fuel injection holes and the front edge of Cavity 2, while L2 indicates the constant distance, which is $45 \mathrm{~mm}$, between the PJ torch and the front edge of Cavity 2.

Fig. 3 shows drawing of the DC plasma torch used in current paper. The input power of the PJ torch, which consisted of a copper-made convergent nozzle with $1.5 \mathrm{~mm}$ diameter throat and 40 degree convergent angle, was set to $1.5 \mathrm{~kW}$. Central-inserted tip-sharpen cathode was made of tungsten. The interval between anode and cathode was preciously controlled to $0.35 \mathrm{~mm}$ using a micro ruler. The PJ torch could work with both $\mathrm{N}_{2}$ and $\mathrm{N}_{2}+\mathrm{H}_{2}$ feedstock, while circulating cooling water was used to avoid anode erosion. For the $\mathrm{N}_{2}$ feedstock, the flow rate of $\mathrm{N}_{2}$ was set to $1.18 \mathrm{~kg} / \mathrm{s}$. And for $\mathrm{N}_{2}+\mathrm{H}_{2}$ feedstock, the flow rate of $\mathrm{N}_{2}$ and $\mathrm{H}_{2}$ were set to $0.94 \mathrm{~g} / \mathrm{s}$ and $0.06 \mathrm{~g} / \mathrm{s}$, respectively. The total pressure of PJ torch feedstock was about 0.6 MPa.

\section{Results and discussion}

\subsection{Ignition and flame propagation}

In order to capture the process of ignition and flame propagation, high speed photography and schlieren photography were performed with a high speed camera (Model: Camrecord 5000, Optronis Inc.). Fig. 4 illustrates the imaging view field of the high speed photograph. Chemiluminescence transmitting Window 2 and Window 3, which correspond to Cavity 2 and Cavity 3 respectively,

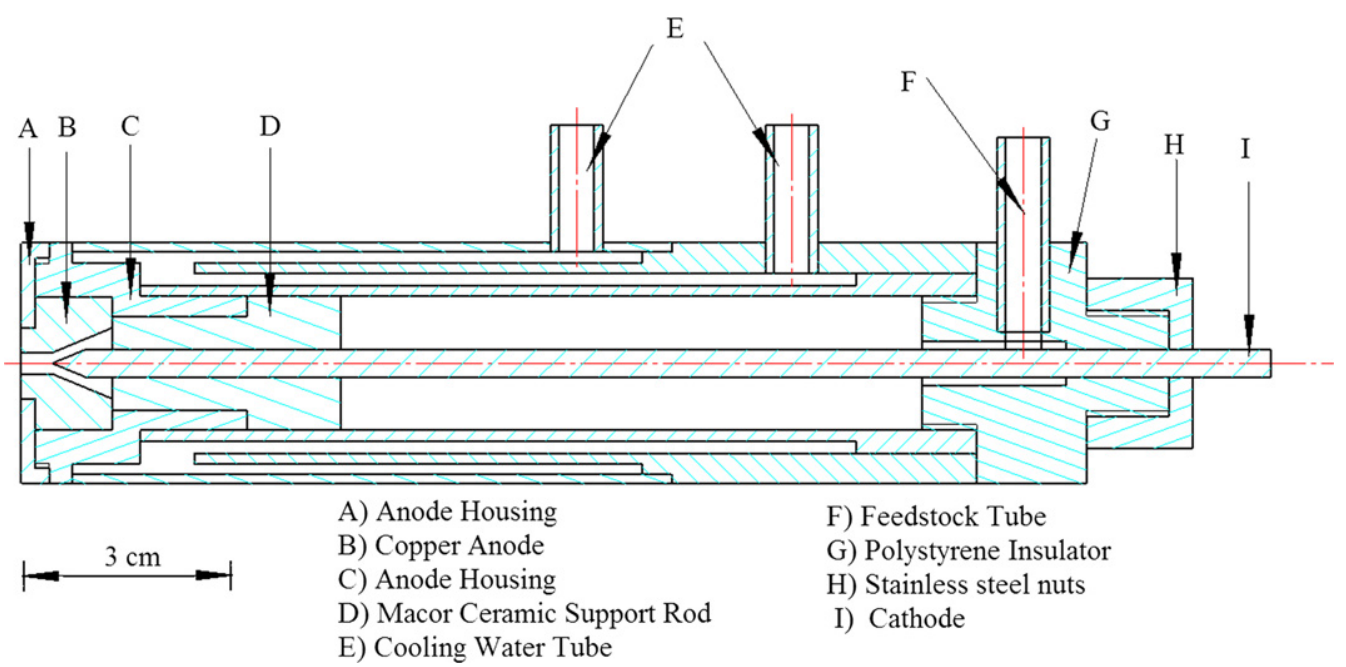

Fig. 3. Drawing of the DC plasma torch used in current work. 


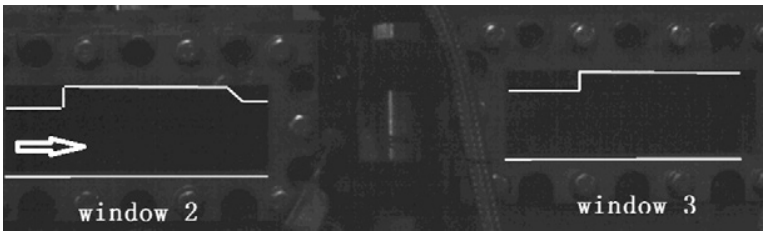

Fig. 4. View field for high speed photograph.

can be recorded by this camera. A set of typical consecutive images of ignition and flame propagation is shown in Fig. 5, while the frame rate was set to $1000 \mathrm{fps}$ and exposure time was one millisecond. The flow direction of main stream is from left to right in all the figures in this paper.

As shown in Fig. 5(a), the PJ torch started to work at time 76 ms. Enlarged range of strong emission meant the ignition of the fuel and air mixture and little flame appearing in the Cavity 2 after one millisecond, as shown in Fig. 5(b). After another one millisecond, as shown in Fig. 5(c), the flame fully propagated in the Cavity 2 and weak emission appeared near Cavity 3, indicating the combustion occurred in the shear layer of Cavity 3. At time $80 \mathrm{~ms}$ (Fig. 5(d)), luminescence appeared in the entire Window 3, which meant the combustion had taken place in the entire channel near Cavity 3. At the same time, flame had propagated to the tail of Cavity 2. Then possible shock train went upstream and ignited the fuel/air mixture in the shear layer of Cavity 2, as shown in Fig. 5(e). Combustion oscillation appeared around Cavity 2, and this phenomenon sustained for about 180 ms, as shown in Fig. 5(e) and (f). Then the flame front went to the upstream of Cavity 2 and chemiluminescence filled of the entire flow channel and kept on quasi-stable state, as shown in Fig. 5(g).

Generally, ignition can take place around the PJ torch or inside the cavity due to high temperature and large amount of radical contained in the hot plasma gas, as shown in Fig. 5(a) and (b). But that cannot guarantee successful ignition for a scramjet. The global ignition can only be achieved when strong luminescence occurred around Cavity 3 and maintained at a stable state (as shown in Fig. 5(c) and (d)), accompanying with much more heat release and pressure increase in downstream [10]. Then shock wave will be pushed upstream and flame front also propagates upstream to fuel injection, as shown in Fig. 5(e).
Table 1

Typical test results.

\begin{tabular}{lllll}
\hline L1 $[\mathrm{mm}]$ & $P_{\text {jet }}[\mathrm{MPa}]$ & Equivalence ratio & Feedstock & Result \\
\hline 550 & 1.5 & 0.20 & $\mathrm{~N}_{2}$ & fail \\
& 2.0 & 0.26 & $\mathrm{~N}_{2}$ & fail \\
& 3.0 & 0.37 & $\mathrm{~N}_{2}$ & fail \\
550 & 1.5 & 0.20 & $\mathrm{~N}_{2}+\mathrm{H}_{2}$ & fail \\
& 2.0 & 0.26 & $\mathrm{~N}_{2}+\mathrm{H}_{2}$ & fail \\
370 & 2 & 0.26 & $\mathrm{~N}_{2}$ & fail \\
280 & 1.5 & 0.20 & $\mathrm{~N}_{2}+\mathrm{H}_{2}$ & success \\
& 2.0 & 0.26 & $\mathrm{~N}_{2}+\mathrm{H}_{2}$ & success \\
& 2.5 & 0.30 & $\mathrm{~N}_{2}+\mathrm{H}_{2}$ & success \\
280 & 1.7 & 0.22 & $\mathrm{~N}_{2}$ & success \\
& 2.0 & 0.26 & $\mathrm{~N}_{2}$ & success \\
280 & 2.5 & 0.30 & $\mathrm{~N}_{2}$ & fail \\
\hline
\end{tabular}

In this study, several tests were performed for a constant power input of the PJ torch. In these tests, the effect of fuel injection pressure and feedstock of the PJ torch were studied as well as torch placement relative to fuel injection site (L1). The results indicated that suitable torch placement and injection pressure are necessary for successful global ignition in Mach 1.8 supersonic flow. The typical results are shown in Table 1 and further analysis will be detailed in the following parts of this paper.

\subsection{Effect of PJ torch placement on ignition}

The ignition tests were carried out for different fuel injection locations. L1 was set to $550 \mathrm{~mm}, 370 \mathrm{~mm}$, and $280 \mathrm{~mm}$, respectively. In these tests, the power of the PJ torch was set to $1.5 \mathrm{~kW}$, with $\mathrm{N}_{2}+\mathrm{H}_{2}$ served as feedstock gas. The fuel injection pressure was $2.0 \mathrm{MPa}$ corresponding to an equivalence ratio of 0.26 . Fig. 6 depicts the pressure distribution along streamwise with different plasma torch locations. And Fig. 7 suggests the high speed photography under these test conditions. As shown in Fig. 6, successful global ignition can only be achieved at $\mathrm{L} 1=280 \mathrm{~mm}$. At this condition, large field combustion occurred at regions near Window 2 and Window 3. It can be further confirmed by the corresponding high speed photography photos, as shown in Fig. 7(c). However,
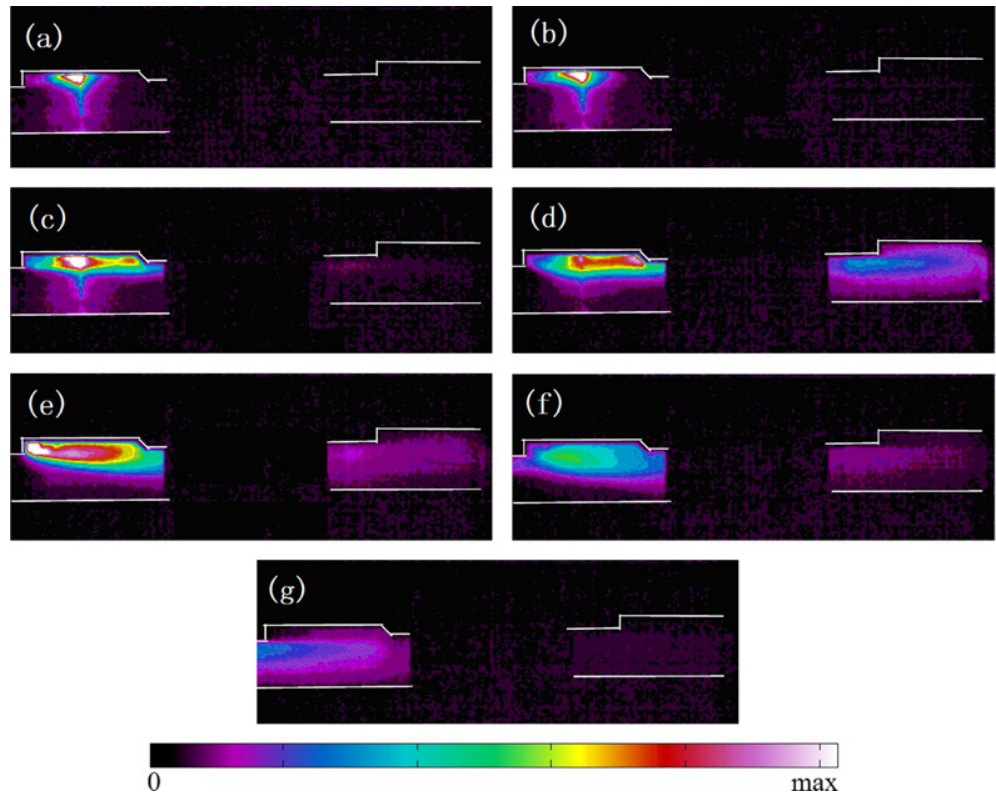

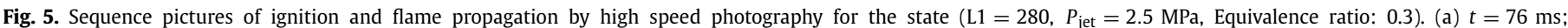
(b) $t=77 \mathrm{~ms}$; (c) $t=78 \mathrm{~ms}$; (d) $t=80 \mathrm{~ms}$; (e) $t=84 \mathrm{~ms}$; (f) $t=165 \mathrm{~ms}$; and (g) $t=264 \mathrm{~ms}$. 


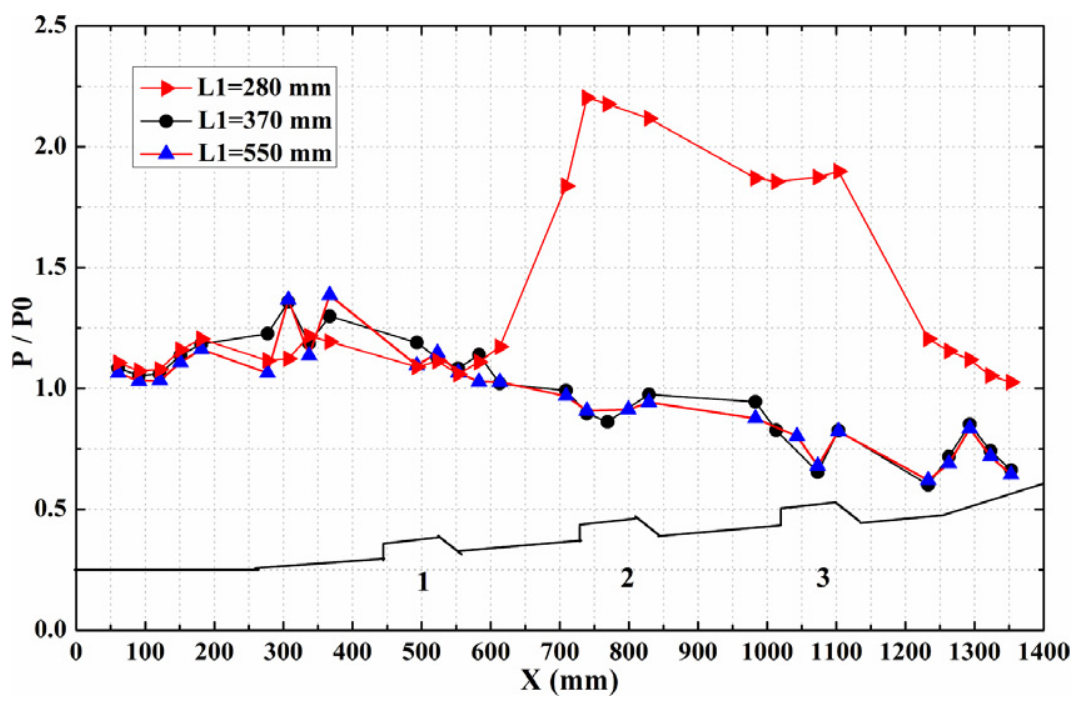

Fig. 6. Pressure distribution along the wall for the tests with the different plasma torch location (PJ feedstock: $\left.\mathrm{N}_{2}+\mathrm{H}_{2}\right)$.
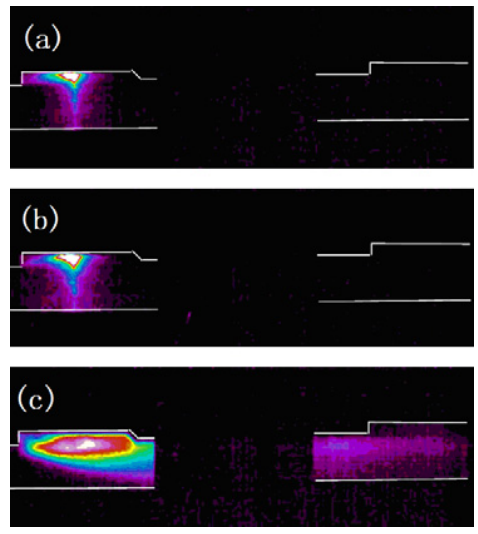

Fig. 7. High speed photography for the tests with the different plasma torch location $\left(P_{\text {jet }}=2 \mathrm{MPa}\right)$. (a) $\mathrm{L} 1=550 \mathrm{~mm}$; (b) $\mathrm{L} 1=370 \mathrm{~mm}$; (c) $\mathrm{L} 1=280 \mathrm{~mm}$.

when injection is placed at $\mathrm{L} 1=550 \mathrm{~mm}$ or $370 \mathrm{~mm}$, stable flame could not occur even in the cavity, which can be found in Fig. 7(a) and (b). Thus the distance between injection and plasma-located cavity (L1) is an important parameter for ignition.

As shown in Table 1, it is obvious that the ignition of liquidkerosene fuel is much more difficult for larger L1. One possible reason is that the relatively slow main-flow speed at Mach 1.8 results in fully mixed kerosene/air gas in a short distance. Another reason is the small equivalence ratio in this case. Larger L1 can lead to not only the better mixing of fuel and air, but also the smaller local equivalence ratio within Cavity 2, which is detrimental for ignition. On the other hand, ignition will be more difficult if L1 is much smaller than $280 \mathrm{~mm}$, corresponding to very short distance between injection location and Cavity 2. For incoming flow at Mach 1.8, the static temperature and total temperature are $600 \mathrm{~K}$ and $900 \mathrm{~K}$ respectively. Such low static air temperature is not favorable for liquid droplet evaporation. Full atomization and evaporation of liquid kerosene require at least a $150 \mathrm{~mm}$ distance at this flow condition. Thus, in general, neither too short nor too long distance between injection and plasma-located cavity (L1) is conducive for plasma ignition.

\subsection{Effect of injection pressure on ignition}

Four groups of tests with different injection pressure were conducted. The first one was the test with injection pressure of $1.5 \mathrm{MPa}$, corresponding to the equivalence ratio $\phi=0.20$. The second one was the test with injection pressure of $1.7 \mathrm{MPa}$, corresponding to the equivalence ratio $\phi=0.22$. The third one was the test with injection pressure of $2.0 \mathrm{MPa}$, corresponding to the equivalence ratio $\phi=0.26$. The fourth one was the test with injection pressure of $2.5 \mathrm{MPa}$, corresponding to the equivalence ratio $\phi=0.30$. The distance between injection location and Cavity 2 for all tests were set at $\mathrm{L} 1=280 \mathrm{~mm}$.

Fig. 8 represents the static pressure distribution along flow direction with different injection pressure. It can be found that global ignition can be achieved for the test with the $\mathrm{N}_{2}+\mathrm{H}_{2}$ plasma torch at injection pressure of $2.5 \mathrm{MPa}$, while ignition could not be realized for the pure $\mathrm{N}_{2}$ plasma torch at the same injection pressure. For several other tests with lower injection pressure and two different plasma torches, the global ignition could be realized. High-speed photography images are shown in Fig. 9 to illustrate the flame front and combustion zone since wall pressure data can only reflect the global-combustion state. Combustion anchors in Cavity 2 and weakly spreads to main flow near Cavity 3 at low equivalence ratio, as shown in Fig. 9(a). When increasing the equivalence ratio, flame front moves upstream to Cavity 2 and stable combustion takes place in the shear layer and the main flow near Cavity 2 (Fig. 9(b)). For much higher equivalence ratio, flame front moves upstream of Cavity 2, and combustion zone fills the entire flow channel (Fig. 9(c)). Unfortunately, thermal choke takes place due to the small expansion angle of the top wall in this study.

Fig. 10 are the images of high-speed schlieren photography, which show the whole propagation process of shock train and flame front. As shown in Fig. 10(a), at $t=68 \mathrm{~ms}$, combustion took place in Cavity 2, and after about $200 \mathrm{~ms}$, pressure wave propagated upstream and shear layer was pushed toward main flow. At the moment of $t=274 \mathrm{~ms}$, the shear layer expanded due to the pressure increase and the shock wave started to move upstream as shown in Fig. 10(c). With the increasing of pressure, the flame front moved upstream and the deformation of shock wave occurred at $t=275 \mathrm{~ms}$, as shown in Fig. 10(d). Then, oscillation of flame front and shock wave occurred near Cavity 2 around $t=277 \mathrm{~ms}$ and $t=279 \mathrm{~ms}$ (Fig. 10(e) and (f)). Shock wave and flame front kept moving upstream (Fig. 10(g)), and at last, the flame front was upstream of window 2 at $t=324 \mathrm{~ms}$ (Fig. 10(h)), corresponding to the pressure distribution shown in Fig. 8.

As shown in this figure, we cannot find the plume of plasma jet even though the torch kept working during the whole test time. There are three reasons for this phenomena, 1) view field about $8 \mathrm{~mm}$ near the top floor of the Cavity 2 was blocked by the steel 


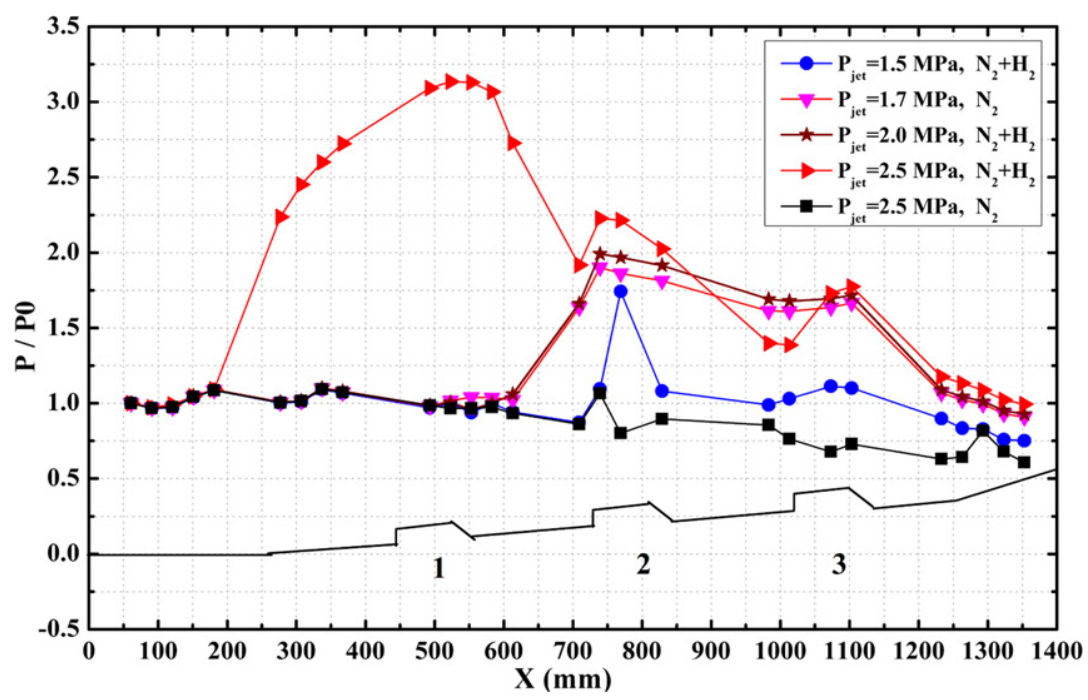

Fig. 8. Pressure distribution along the wall for tests with different injection pressure and plasma torch.
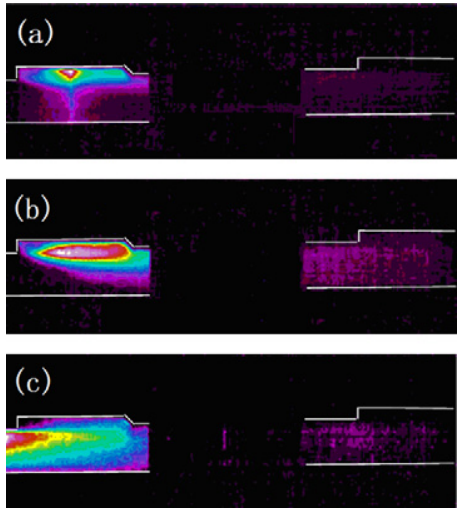

Fig. 9. High-speed photography for the tests with different injection pressure (feed stock gas: $\mathrm{N}_{2}+\mathrm{H}_{2}$ ). (a) $P_{\text {jet }}=1.5 \mathrm{MPa}, \Phi=0.20$; (b) $P_{\text {jet }}=2 \mathrm{MPa}, \Phi=0.26$ and (c) $P_{\text {jet }}=2.5 \mathrm{MPa}, \Phi=0.30$.

edges of the window inserts as shown in Fig. 1,2) the exposure time of these schlieren images is only one microsecond while the exposure time of high-speed photography shown in Figs. 5, 7 and 9 is one millisecond, thus it is too short to record the luminescence of the plume, 3) the "schlieren effect" is quite weak due to the small throat diameter of $1.5 \mathrm{~mm}$.

\subsection{Effect of plasma feedstock on ignition}

Fig. 8 also indicates that the feedstock of PJ torch has influence on its ignition performance. PJ torches with feedstock of $\mathrm{N}_{2}+\mathrm{H}_{2}$ and pure $\mathrm{N}_{2}$, can both ignite kerosene at injection pressure less than 2.0 MPa. However, at injection pressure of 2.5 MPa, PJ torch with $\mathrm{N}_{2}+\mathrm{H}_{2}$ feedstock successfully ignites the liquid fuel while the pure- $\mathrm{N}_{2}$ PJ torch does not. As will be investigated in the following section, higher injection pressure results in better global equivalence-ratio but poor local equivalence-ratio in the cavity. Therefore, it requires stronger ignition performance of PJ torch for higher injection pressure.

Our explanation to the superiority of the $\mathrm{N}_{2}+\mathrm{H}_{2}$ feedstock is that this $\mathrm{PJ}$ torch can generate both $\mathrm{H}$ radical and extra heat release in local ignition zone. $\mathrm{H}$ radical in the plume of $\mathrm{N}_{2}+\mathrm{H}_{2}$ PJ can significantly decrease the ignition delay [25] and increase burning velocity which can stabilize flame in high speed flow [23]. Furthermore, the flow rate of $\mathrm{H}_{2}$ in the $\mathrm{N}_{2}+\mathrm{H}_{2} \mathrm{PJ}, 0.06 \mathrm{~g} / \mathrm{s}$, results in heat release about $8.5 \mathrm{~kJ} / \mathrm{s}$ in the small plume zone (about
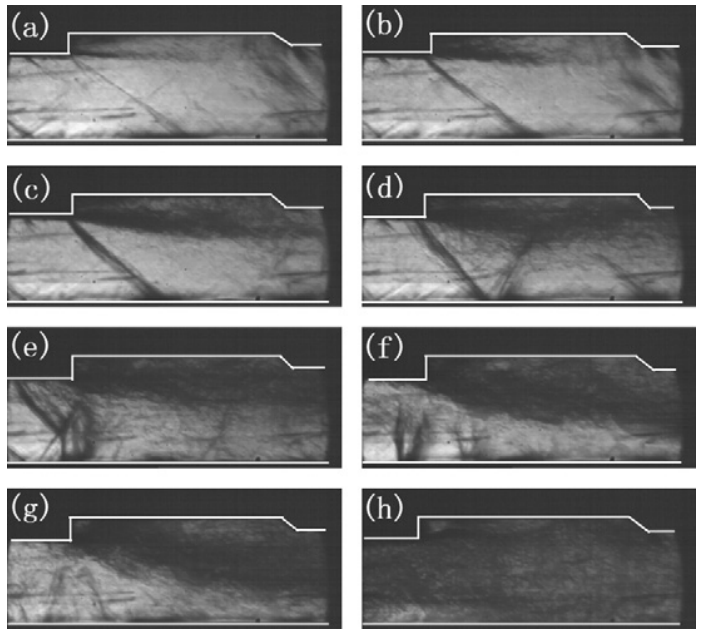

Fig. 10. Sequence images of flame front moving upstream process by high speed schlieren ( $\mathrm{L} 1=280 \mathrm{~mm}, P_{\text {jet }}=2.5 \mathrm{MPa}$, equivalence ratio 0.3 , viewfield: window 2). (a) $t=68.5 \mathrm{~ms}$; (b) $t=273 \mathrm{~ms}$; (c) $t=274 \mathrm{~ms}$; (d) $t=275.2 \mathrm{~ms}$; (e) $t=$ $276.7 \mathrm{~ms}$; (f) $t=278 \mathrm{~ms}$; (g) $t=317.3 \mathrm{~ms}$; and (h) $t=324.3 \mathrm{~ms}$.

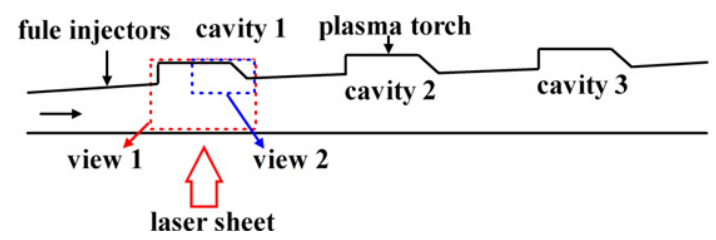

Fig. 11. Schematic diagram of PLS imaging range and laser sheet arrangement.

$\phi 3 \mathrm{~mm} \times 10 \mathrm{~mm}$, based on former experiments). Comparing to the $1.5 \mathrm{~kW}$ input power of $\mathrm{PJ}$ torch, this extra heat release can increase local gas temperature and also enhance ignition and flame stability. The undergoing research is to investigate the ignition performance of PJ torch with different feedstock gas.

\subsection{Effect of liquid kerosene atomization on ignition}

As aforementioned analysis, local equivalence ratio of fuel air mixture is considered as the most important factor affecting ignition. In order to estimate the local equivalence ratio in the igniting cavity, it is very important to determine the penetration depth of liquid fuel and the characteristic length of fuel atomization and evaporation in supersonic flow. Thus, planar laser scattering (PLS) 

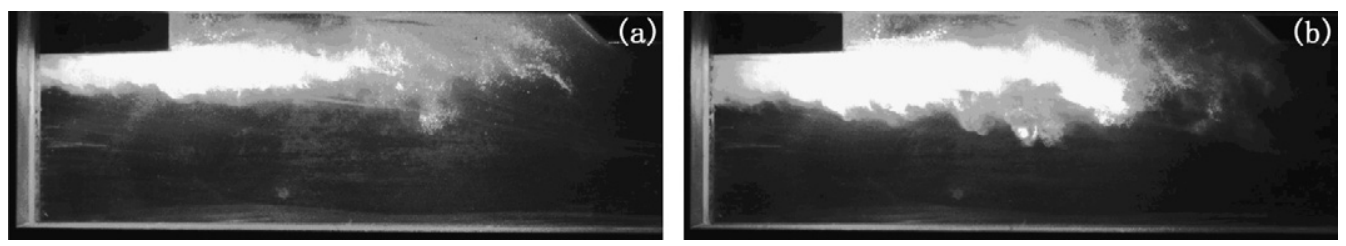

Fig. 12. PLS image of liquid kerosene jet for different injection pressure, view 1. (a) $P_{\text {jet }}=1.5 \mathrm{MPa}$ and (b) $P_{\text {jet }}=3 \mathrm{MPa}$; main flow is from left to right.
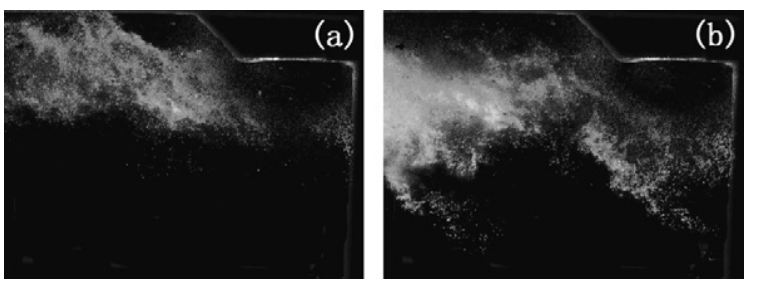

Fig. 13. PLS image of liquid kerosene jet for different injection pressure, view 2. (a) $P_{\text {jet }}=1.5 \mathrm{MPa}$ and (b) $P_{\text {jet }}=3 \mathrm{MPa}$; main flow is from left to right.

technique was employed for analyzing the evaporation of liquid fuel and the spatial distribution of gaseous fuels [6].

The schematic diagram of imaging range and laser sheet arrangement of PLS is shown in Fig. 11. The PLS technique, which is based on Mie scattering of particles, is only effective when particles exist. Unfortunately, the PLS does not work while taking an image using PLS near the area around Cavity 2, due to the full evaporation of kerosene droplets there. Therefore, we focus the area of interest on the region around Cavity 1, where a large amount of particles exist. And the PLS images near Cavity 1 are used for estimating the distribution of gaseous kerosene near Cavity 2. In order to obtain more detailed information, two regions in Window 1 were selected for imaging small kerosene droplets. The first one was the area of entire Window 1 with view field $150 \mathrm{~mm} \times 50 \mathrm{~mm}$ (labeled as View 1 in Fig. 11). The second one was the area of the trailing edge of Cavity 1 with view field $42 \mathrm{~mm} \times 32 \mathrm{~mm}$ (labeled as View 2 in Fig. 11). During the tests, the laser energy was $20 \mathrm{~mJ} /$ pulse@532nm and the pulse duration was $10 \mathrm{~ns}$. The thickness of laser sheet was optically controlled as $0.3 \mathrm{~mm}$.

Fig. 12 and Fig. 13 represent the typical PLS images for different fuel injection pressures ( $P_{\text {jet }}=1.5 \mathrm{MPa}$ and $3 \mathrm{MPa}$ ). Strong bright area in Fig. 12 means the existing of large amounts of particles and the grey area means small amounts of small particles, while black region means no droplets. These images indicate that the characteristic length of kerosene-jet atomization and evaporation is about $150 \mathrm{~mm}$ for both $P_{\text {jet }}=1.5 \mathrm{MPa}$ and $P_{\text {jet }}=3.0 \mathrm{MPa}$, under the condition of Mach 1.8 and total temperature of $950 \mathrm{~K}$.

At higher injection-pressure, penetration depth is higher due to relatively large momentum, but poor atomization takes place around the leeward side of kerosene jet column. As shown in Fig. 12(b), the fuel penetration depth near Cavity 1 is about the half height of flow channel, at injection pressure $P_{\text {jet }}=3.0 \mathrm{MPa}$. The fuel jet exhibits significant downward trend toward the bottom wall. On the opposite side, the kerosene droplets slip across the shear layer and only a little account of droplets are involved into the cavity. For injection pressure of $1.5 \mathrm{MPa}$, as shown in Fig. 12(a), penetration depth is only the $1 / 3$ height of the flow chancel. Except for a little part of jet drifted toward the core flow by the large scale eddy structures, the entire jet exhibits the trend of expansion to the cavity due to the relative small jet momentum. Since smaller the penetration depth and the more excellent leeward-crushing effect, the local equivalence ratio in the cavity is much better than the higher injection pressure case. Fig. 13 represents typical PLS images at View 2 region for the injection pressure of $1.5 \mathrm{MPa}$ and 3.0 MPa. As shown in Fig. 13(a), a considerable number of kerosene droplets exist in the cavity for injection pressure of $1.5 \mathrm{MPa}$ and kerosene droplets only exist in the region $10 \mathrm{~mm}$ away from the top wall after the trailing edge of Cavity 1 . As the increasing of injection-pressure, kerosene droplets spread from the top wall into the core flow, resulting in significant fuel particles reduction inside cavity. Therefore, the kerosene going into downstream Cavity 2 (PJ located cavity) is relatively reduced, which would increase the difficulty for ignition. Thus, for experiments at small global equivalent ratio and cavity ignition, lower injection pressure can increase the reliability of ignition due to a suitable fuel/air equivalent ratio in ignition-cavity.

\section{Conclusion}

By using a plasma jet (PJ) torch with $1.5 \mathrm{~kW}$ input power as an igniter, successful ignition for liquid-kerosene fueled combustion experiment was conducted in a direct-connected supersonic test facility at Mach 1.8 and total temperature $950 \mathrm{~K}$. The process of ignition and flame front propagation were obtained through high speed photography and high speed schlieren photography. Combining with the wall static pressure distribution, the conclusion has been drawn as following:

(1) When the distance between the PJ torch and location of fuel injection holes (L1) was set to $280 \mathrm{~mm}$, injection pressure was set from 1.5 to $2.5 \mathrm{MPa}$ (equivalence ratio 0.2-0.3), successful ignition of liquid kerosene was realized without additive $\mathrm{H}_{2}$ pilot, while global ignition cannot be achieved with the increase of L1.

(2) Ignition capacity of a PJ torch with $\mathrm{N}_{2}+\mathrm{H}_{2}$ feedstock is better than a PJ torch with pure $\mathrm{N}_{2}$ feedstock. However, there is no remarkable difference in the maintenance characteristics of flame once ignition was achieved.

(3) The distribution of kerosene droplets along flow direction was also studied by using planar laser scattering (PLS) technique, which indicates that local equivalence ratio inside the cavity is the key factor affecting ignition. As the injection pressure increases, the penetration depth increases, which is benefit for the organization of combustion in the large field. Meanwhile, concentration distribution of kerosene near the top wall is reduced. Thus, it is unfavorable for ignition inside the cavity at high injection pressure experiments cases.

\section{Acknowledgements}

The work is partially supported by National Science Foundation of China (Grant Nos. 90816015 and 10772188). The authors acknowledge the technical assistance provided by D.H. Song and Z.M. Luo at the Institute of Mechanics, Chinese Academy of Sciences.

\section{References}

[1] M.C. Billingsley, W.F. O'Brien, J.A. Schetz, Plasma torch atomizer-igniter for supersonic combustion of liquid hydrocarbon fuels, AIAA Paper 2006-7970, 2006.

[2] E.T. Curran, Scramjet engines: the first forty years, J. Propul. Power 17 (6) (2001) 1138-1148.

[3] M. Ding, Z. Wang, Experimental investigation on drag of cavity flame holder, Acta Aeronautica et Astronautica Sinica 27 (4) (2007) 556. 
[4] M. Ding, J. Wu, J. Liang, W. Liu, et al., Application of control technology based on Venturi in kerosene fueled scramjet, J. Propul. Technol. 26 (1) (2005) 16-19 (in Chinese).

[5] H. Do, M.A. Cappelli, M.G. Mungal, Plasma assisted cavity flame ignition in supersonic flows, Combust. Flame 157 (9) (2010) 1783-1794.

[6] C. Grueniga, F. Mayinger, Supersonic combustion of kerosene $/ \mathrm{H}_{2}$-mixtures in a model scramjet combustor, Combust. Sci. Technol. 146 (1-6) (1999) 1-22.

[7] H.B. Gu, L.H. Chen, X.Y. Chang, Experimental investigation on the cavity-based scramjet model, Chinese Sci. Bull. 54 (16) (2009) 2794-2799.

[8] L.S. Jacobsen, C.D. Carter, T.A. Jackson, et al., Plasma-assisted ignition in scramjets, J. Propul. Power 24 (4) (2008) 641-654.

[9] L.S. Jacobsen, S.D. Gallimore, J.A. Schetz, W.F. O'Brien, Integration of an aeroramp injector/plasma igniter for hydrocarbon scramjets, J. Propul. Power 19 (2) (2003) 170-182.

[10] K. Kobayashi, S. Tomioka, K. Kato, et al., Performance of a dual-mode combustor with multistaged fuel injection, J. Propul. Power 22 (3) (2006) 518-526.

[11] K. Kobayashi, S. Tomioka, T. Mitani, Supersonic flow ignition by plasma torch and $\mathrm{H}_{2} / \mathrm{O}_{2}$ torch, J. Propul. Power 20 (2) (2004) 294-301.

[12] K. Kumaran, V. Babu, Mixing and combustion characteristics of kerosene in a model supersonic combustor, J. Propul. Power 25 (3) (2009) 583-592.

[13] S.P. Kuo, D. Bivolaru, A pulsed plasma torch and its performance in a Mach 2.5 supersonic flow, IEEE Trans. Plasma Sci. 34 (1) (2006) 63-69.

[14] S.B. Leonov, I.V. Kochetov, A.P. Napartovich, V.A. Sabel'nikov, et al., Plasmainduced ethylene ignition and flameholding in confined supersonic air flow at low temperatures, IEEE Trans. Plasma Sci. 39 (2) (2011) 781-787.

[15] G. Masuya, K. Takita, K. Takahashi, F. Takatori, et al., Effects of airstream Mach number on $\mathrm{H}_{2} / \mathrm{N}_{2}$ plasma igniter, J. Propul. Power 18 (3) (2002) 679-685.

[16] D.J. Micka, J.F. Driscoll, Combustion characteristics of a dual-mode scramjet combustor with cavity flameholder, Proc. Combust. Inst. 32 (2) (2009) 23972404.

[17] Y. Pan, M. Ding, J. Liang, et al., Analysis of internal drag of scramjet engine with multi-cavities in tandem, Acta Aeronautica et Astronautica Sinica 31 (1) (2010) 70-75.
[18] C.C. Rasmussen, J.F. Driscoll, K.Y. Hsu, et al., Stability limits of cavity-stabilized flames in supersonic flow, Proc. Combust. Inst. 30 (2) (2005) 2825-2833.

[19] K. Shuzenji, T. Tachibana, Superiority of oxygen as feedstock for a plasma jet igniter in supersonic methane/air streams, Proc. Combust. Inst. 29 (1) (2002) 875-881.

[20] W. Song, W. He, H. Bai, Experimental investigation of plasma ignition in supersonic combustor, J. Exp. Fluid Mech. 20 (4) (2006) 20-24 (in Chinese).

[21] K. Takita, Ignition and flame-holding by oxygen, nitrogen and argon plasma torches in supersonic airflow, Combust. Flame 128 (3) (2002) 301-313.

[22] K. Takita, N. Abe, G. Masuya, Y. Ju, Ignition enhancement by addition of NO and $\mathrm{NO}_{2}$ from a $\mathrm{N}_{2} / \mathrm{O}_{2}$ plasma torch in a supersonic flow, Proc. Combust. Inst. 31 (2) (2007) 2489-2496.

[23] K. Takita, G. Masuya, T. Sato, et al., Effect of addition of radicals on burning velocity, AIAA J. 39 (4) (2001) 742-744

[24] K. Takita, K. Murakami, H. Nakane, G. Masuya, A novel design of a plasma jet torch igniter in a scramjet combustor, Proc. Combust. Inst. 30 (2) (2005) 28432849.

[25] K. Takita, R. Ohashi, N. Abe, Suitability of $\mathrm{C}_{2-}, \mathrm{C}_{3}$-hydrocarbon fuels for plasma ignition in high-speed flow, J. Propul. Power 25 (3) (2009) 565-570.

[26] K. Takita, K. Shishido, K. Kurumada, Ignition in a supersonic flow by a plasma jet of mixed feedstock including $\mathrm{CH}_{4}$, Proc. Combust. Inst. 33 (2) (2011) 23832389.

[27] K. Takita, T. Uemoto, T. Sato, Y.G. Ju, et al., Ignition characteristics of plasma torch for hydrogen jet in an airstream, J. Propul. Power 16 (2) (2000) 227-233.

[28] V.A. Vinogradov, S.A. Kobigsky, M.D. Petrov, Experimental investigation of kerosene fuel combustion in supersonic-flow, J. Propul. Power 11 (1) (1995) 130-134.

[29] G. Yu, J.G. Li, J.R. Zhao, et al., An experimental study of kerosene combustion in a supersonic model combustor using effervescent atomization, Proc. Combust. Inst. 30 (2) (2005) 2859-2866.

[30] A.M. Yvette Zuzeek, I. Choi, M. Nishihara, I.V. Adamovich, et al., Energy coupling and heat release in air and ethylene-air nanosecond pulse discharge plasmas, AIAA Paper 2009-3591, 2009. 